\title{
Sarcolemmal ATP-sensitive potassium channel protects cardiac myocytes against lipopolysaccharide-induced apoptosis
}

\author{
XIAOHUI ZHANG ${ }^{1}$, XIAOHUA ZHANG ${ }^{2}$, YIQUN XIONG ${ }^{1}$, CHAOYING XU $^{1}$, XINLIANG LIU ${ }^{1}$, \\ JIAN LIN ${ }^{1}$, GUIPING MU ${ }^{1}$, SHAOGANG XU ${ }^{1}$ and WENHE LIU ${ }^{1}$ \\ ${ }^{1}$ Central Laboratory, Shenzhen Hospital Affiliated to Guangzhou University of Traditional Chinese Medicine, Shenzhen, \\ Guangdong 518033, P.R. China; ${ }^{2}$ Cardiac Signaling Center, Medical University of South Carolina, Charleston, SC 29425, USA
}

Received July 20, 2015; Accepted June 21, 2016

DOI: $10.3892 / \mathrm{ijmm} .2016 .2664$

\begin{abstract}
The sarcolemmal ATP-sensitive $\mathrm{K}^{+}\left(\operatorname{sarcK}_{\mathrm{ATP}}\right)$ channel plays a cardioprotective role during stress. However, the role of the sarcK $_{\mathrm{ATP}}$ channel in the apoptosis of cardiomyocytes and association with mitochondrial calcium remains unclear. For this purpose, we developed a model of LPS-induced sepsis in neonatal rat cardiomyocytes (NRCs). The TUNEL assay was performed in order to detect the apoptosis of cardiac myocytes and the MTT assay was performed to determine cellular viability. Exposure to LPS significantly decreased the viability of the NRCs as well as the expression of Bcl-2, whereas it enhanced the activity and expression of the apoptosis-related proteins caspase- 3 and Bax, respectively. The sarcK ${ }_{\mathrm{ATP}}$ channel blocker, HMR-1098, increased the apoptosis of NRCs, whereas the specific sarcK $\mathrm{ATP}_{\mathrm{AT}}$ channel opener, P-1075, reduced the apoptosis of NRCs. The mitochondrial calcium uniporter inhibitor ruthenium red (RR) partially inhibited the pro-apoptotic effect of HMR-1098. In order to confirm the role of the sarcK $\mathrm{ATP}_{\mathrm{AT}}$ channel, we constructed a recombinant adenovirus vector carrying the $\operatorname{sarcK}_{\mathrm{ATP}}$ channel mutant subunit Kir6.2AAA to inhibit the channel activity. Kir6.2AAA adenovirus infection in NRCs significantly aggravated the apoptosis of myocytes induced by LPS. Elucidating the regulatory mechanisms of the $\operatorname{sarcK}_{\text {ATP }}$ channel in apoptosis may facilitate the development of novel therapeutic targets and strategies for the management of sepsis and cardiac dysfunction.
\end{abstract}

\section{Introduction}

Sepsis, also known as systemic inflammatory response syndrome (SIRS), is caused by infection associated with organ damage. Sepsis is a life-threatening condition characterized by rapid progression and a high fatality rate. The mortality rate of

Correspondence to: Dr Xiaohui Zhang, Central Laboratory, Shenzhen Hospital Affiliated to Guangzhou University of Traditional Chinese Medicine, 1 Fuhua Road, Shenzhen, Guangdong 518033, P.R. China

E-mail: 767682665@qq.com

Key words: sarcolemmal ATP-sensitive potassium channel, sepsis, apoptosis, mitochondrial calcium sepsis is complicated by heart failure and may reach 70-90\% (1). Cardiac dysfunction in sepsis is a complex pathophysiological process and the mechanisms underlying sepsis-induced myocardial dysfunction remain to be elucidated. Pro-inflammatory cytokines (such as tumor necrosis factor (TNF)- $\alpha$ and interleukin (IL)-1), endothelin-1, nitric oxide and adhesion molecules act directly or indirectly to suppress cardiac function in sepsis, which results in myocardial dysfunction (2).

Apoptosis has been reported to play an important role in sepsis-induced cardiac dysfunction (3). The pharmacological inhibition of cardiac apoptosis prevents sepsis-induced myocardial dysfunction (4). Although a number of mediators and pathways have been associated with apoptosis which occurs in septic myocardial dysfunction, the precise cause remains elusive.

The ATP-sensitive $\mathrm{K}^{+}\left(\mathrm{K}_{\mathrm{ATP}}\right)$ channels, first discovered in the heart more than 20 years ago, represent a unique group of channels that are regulated predominantly by the cellular metabolic state (5). The function of the cardiac sarcolemmal $\mathrm{K}_{\mathrm{ATP}}\left(\mathrm{sarcK}_{\mathrm{ATP}}\right)$ channel was initially associated with the cardiac response to stress (5), and this was later confirmed by a number of studies. The opening of sarcK $\mathrm{K}_{\mathrm{ATP}}$ channels under conditions of metabolic stress affects excitability and other membrane potential-related functions, such as $\mathrm{Ca}^{2+}$ loading, thus, helping to maintain cellular homeostasis during cardiac challenge (5). Studies suggest that the opening of $\mathrm{K}_{\text {ATP }}$ channels prevents activation of the inflammatory process and the production of a variety of pro-inflammatory factors in microglial cells (6), and blocks the apoptosis of cardiocytes in ischemia-reperfusion (7). $\mathrm{K}_{\mathrm{ATP}}$ channels also play an essential role in the cardiovascular adaptive response during stress (8). Furthermore, Buckley et al proposed that the opening of $\mathrm{K}_{\mathrm{ATP}}$ channels may actually represent a protective mechanism against cellular damage in endotoxemia (9). Several researchers have reported that $\mathrm{K}_{\mathrm{ATP}}$ channels open in sepsis (10-12); however, whether or not they exert a regulatory effect on the apoptosis of septic myocytes has yet to be determined. It is well established that sepsis releases lipopolysaccharide (LPS) into the circulation. LPS exerts a deleterious effect on cardiac function and plays a significant role in the development of acute and chronic heart failure (13). In the present study, we examined the role of cardiac sarcK $\mathrm{K}_{\mathrm{ATP}}$ channels in the LPS-induced apoptosis of cultured neonatal rat cardiomyocytes (NRCs). Furthermore, we identified the downstream effects of cardiac sarcK $\mathrm{K}_{\mathrm{ATP}}$ channel inhibition and 
activation by focusing on the interaction between the $\operatorname{sarcK}_{\text {ATP }}$ channel and mitochondrial calcium.

\section{Materials and methods}

Animals. The animal studies were conducted in accordance with the guidelines of the Experimental Animal Center of Guangdong Province (Guangzhou, China). This study was approved by the Ethics Committee of Guangzhou University of Traditional Chinese Medicine (Shenzhen, China). The rats were housed in a temperature- and humidity-controlled room under a 12-h light/dark cycle prior to the beginning of the experiments. No anesthetics were administered in order to avoid interference with biochemical values.

Reagents. LPS from Escherichia coli serotype 055:B5 was purchased from Sigma-Aldrich (St. Louis, MO, USA). A terminal deoxynucleotidyl transferase-mediated dUTP nick end labeling (TUNEL) kit was purchased from Roche (Mannheim, Germany). Assay kits for the determination of caspase-3 activity were purchased from Beyotime Institute of Biotechnology (Haimen, China).

Cultured NRCs. Primary cultures of NRCs were prepared from the ventricles of 1-3-day-old Sprague-Dawley rats, as described previously (14), with some modifications. Briefly, the neonatal rats were decapitated, the hearts were excised, and ventricular myocardium was sectioned into $1 \mathrm{~mm}^{3}$-thick slices and incubated with $0.25 \%$ trypsin $(3-5 \mathrm{ml})$ in a shaker at $37^{\circ} \mathrm{C}$ for fractionated digestion. The tissue pieces were allowed to settle, and all the supernatant was collected, and centrifuged at $1,000 \mathrm{x} g$ for $10 \mathrm{~min}$. The supernatant was discarded, and a single cell suspension was obtained with Dulbecco's modified Eagle's medium (DMEM) containing 20\% fetal bovine serum (FBS). Ventricular myocytes were separated from the faster-attaching nonmyocytes. The ventricular myocytes in the supernatant were collected and plated on a 12 -well culture plate. The NRCs were used for experiments following a demonstration of confluence and rhythmic contraction after $72 \mathrm{~h}$. To explore the roles of $\operatorname{sarcK}_{\text {ATP }}$ channel and mitochondrial calcium in the LPS-induced apoptosis of myocytes, the following activators and blockers were used: sarcK $_{\text {ATP }}$ channel opener (P-1075, $100 \mu \mathrm{M}$ ), sarcK $_{\mathrm{ATP}}$ channel blocker (HMR-1098, $30 \mu \mathrm{M}$ ) and mitochondrial $\mathrm{Ca}^{2+}$ uniporter inhibitor [ruthenium red (RR), $50 \mu \mathrm{M}]$, respectively. They were applied following stimulation with $25 \mu \mathrm{g} / \mathrm{ml}$ LPS or vehicle for $24 \mathrm{~h}$. The negative control included cells maintained in DMEM containing 10\% FBS with or without inhibitors and not exposed to LPS challenge.

Analysis of cardiomyocyte viability. The cytotoxic effects of LPS on cardiac myocytes were measured using the 3-(4,5-dimethylthiazol-2-yl)-2,5-diphenyl tetrazolium bromide (MTT) assay and the optimal exposure time and dose of LPS was established. Exogenous MTT was reduced to insoluble purple crystal sediment, which dissolves in dimethyl sulfoxide (DMSO), within the cells by mitochondrial succinate dehydrogenase in the viable cells, but not in the dead cells. The cells were seeded in 96-well plates at a density of $5 \times 10^{4}$ cells/well. The cardiomyocytes were incubated with $20 \mu \mathrm{l}$ MTT solution (5 mg/ml; HyClone, Logan, UT, USA) for $4 \mathrm{~h}$ at $37^{\circ} \mathrm{C}$. Next, $150 \mu \mathrm{l}$ DMSO (HyClone) was added to each well to dissolve the formazan crystals, and the plate was agitated for $10 \mathrm{~min}$ until all the crystals were dissolved. The amount of MTT formazan was quantified by determining the absorbance at $570 \mathrm{~nm}$ using a microplate reader (ELX808; Biotek, Winooski, VT, USA). The viability was calculated as follows: viability $(\%)=($ A570, sample-A570, blank $) /(\mathrm{A} 570$, control-A570, blank) x100.

Assessment of apoptosis by TUNEL assay. Apoptosis was analyzed by TUNEL assay (Roche) and Hoechst 33258 staining (H1399; Invitrogen, Carlsbad, CA, USA) according to the manufacturer's instructions. The TUNEL assay was used in order to detect DNA strand breaks. Briefly, the NRCs were grown on laminin-coated chamber slides and exposed to LPS challenge as described above. Twenty-four hours later, the cells were fixed in $4 \%$ paraformaldehyde (PFA) for $1 \mathrm{~h}$, and the TUNEL assay was performed, according to the manufacturer's instructions using a commercial kit (Roche). Apoptotic nuclei stained with fluorescein isothiocyanate (FITC; TUNEL assay) were visualized by confocal microscopy (FV1000; Olympus, Tokyo, Japan). TO-PRO ${ }^{\circledR}-3$ stain was used to stain all nuclei. TUNELpositive cells were counted and the number of apoptotic cells was expressed as a percentage of the total number of cells.

Expression of recombinant adenovirus vector containing subunits of $K_{A T P}$ channel mutant Kir6.2AAA in primary cultured NRCs. A recombinant adenovirus vector carrying $\mathrm{K}_{\mathrm{ATP}}$ channel mutant subunit Kir6.2AAA was constructed and expressed in rat cardiomyocytes. Based upon primers for Kir6.2 sites, site-directed mutagenesis of Kir6.2 GFG amino acids into AAA was performed by means of overlap polymerase chain reaction (PCR). PCR products were cloned into a pShuttle vector for sequence analysis. After PmeI linearization, it was transformed into the adenovirus expression vector pAdEasy-1. The pAdEasy-1 vector was then packaged into a liposome and transfected into primary cultured rat cardiomyocytes. The green fluorescent protein (GFP)-expressing vector (Invitrogen, Shanghai, China) was used as a control. The expression of Kir6.2AAA was confirmed by RT-PCR and western blot analysis. The effects on the LPS-induced apoptosis of myocytes were observed in the presence or absence of LPS.

Caspase-3 activity. To measure caspase-3 enzymatic activity, the NRCs were cultured for $48 \mathrm{~h}$ followed by treatment with P-1075 $(100 \mu \mathrm{M})$, HMR-1098 $(30 \mu \mathrm{M})$ and/or RR $(50 \mu \mathrm{M})$ for $30 \mathrm{~min}$ following treatment with or without LPS $(25 \mu \mathrm{g} / \mathrm{ml})$. The activity of caspase- 3 was determined using a caspase assay kit (Beyotime Institute of Biotechnology) based on the ability of caspase-3 to change acetyl-Asp-Glu-Val-Asp p-nitroanilide (Ac-DEVD-pNA) into a yellow formazan product p-nitroaniline (pNA). Protein concentrations were determined using a Bradford protein assay (Bio-Rad, Hercules, CA, USA).

Western blot analysis. Cultured myocytes were harvested and lysed for $30 \mathrm{~min}$ on ice in lysis buffer $(20 \mathrm{mM}$ Tris-HCl, $\mathrm{pH} 7.5$, $150 \mathrm{mM} \mathrm{NaCl}, 1 \% \mathrm{NP}-40,10 \%$ glycerol, $0.4 \mathrm{mM}$ sodium orthovanadate, $10 \mathrm{mM}$ sodium pyrophosphate, $10 \mathrm{mM}$ sodium fluoride, $0.5 \mathrm{mM}$ dithiothreitol (DTT) and $2 \mu \mathrm{l} / \mathrm{ml}$ protease inhibitor). Following $15 \mathrm{~min}$ of centrifugation at 12,000 $\mathrm{x} \mathrm{g}$ and 

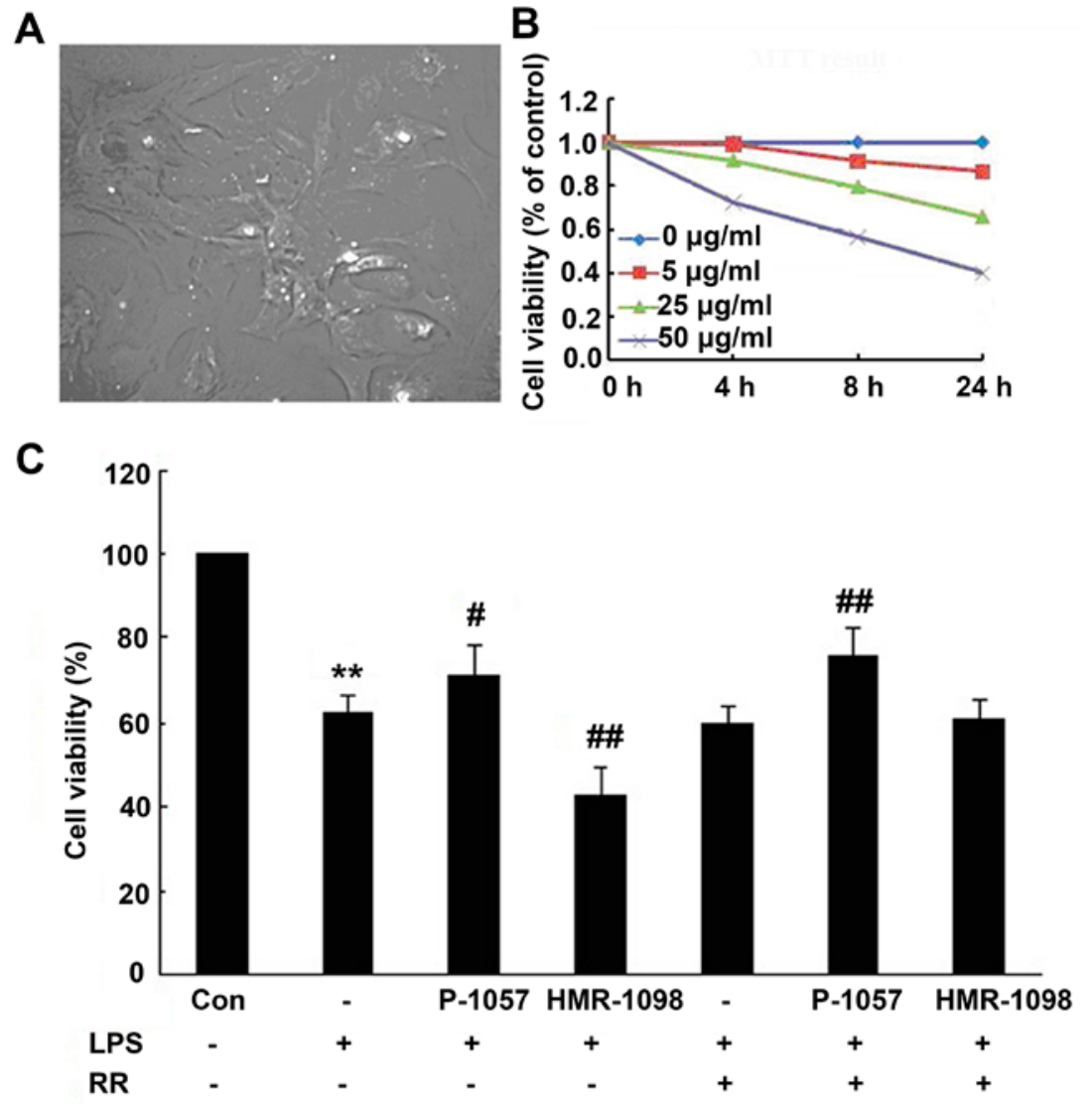

Figure 1. Effects of sarcolemmal ATP-sensitive $\mathrm{K}^{+}\left(\operatorname{sarcK}_{\mathrm{ATP}}\right)$ channel and mitochondrial calcium on cell viability in neonatal rat cardiomyocytes (NRCs) exposed to lipopolysaccharide (LPS). (A) Primary cultured NRCs (x200 magnification): NRCs were isolated by the method of pancreatic enzyme digestion and differential attaching, and were of high purity and exhibited fusiform or short rod branch shapes and spontaneous pulsation. (B) Dose- and time-dependent effects of LPS on cell viability. Cell viability was determined using an MTT assay. (C) Bar graph shows the average values of cell viability for each group. All values are presented as the means $\pm \mathrm{SD} .{ }^{* *} \mathrm{P}<0.01$ vs. control (Con) group; ${ }^{~} \mathrm{P}<0.05$ and ${ }^{\# \#} \mathrm{P}<0.01$ vs. LPS group. $\mathrm{n}=6$ in each group.

$4^{\circ} \mathrm{C}$, the supernatants were obtained and used in subsequent experiments. Equal amounts of protein from each sample were resolved on sodium dodecyl sulfate (SDS)-polyacrylamide gel by electrophoresis, and transferred to Immobilon polyvinylidene difluoride (PVDF) membranes (Millipore, Billerica, MA, USA), blocked with 5\% BSA in TBST (20 mM Tris-HCl, $137 \mathrm{mM} \mathrm{NaCl}$, and $0.1 \%$ Tween-20, $\mathrm{pH} 7.5$ ) at room temperature for $1 \mathrm{~h}$. The membranes were incubated with primary antibodies overnight at $4^{\circ} \mathrm{C}$. Following incubation with horseradish peroxidase (HRP)conjugated secondary antibodies (1:3,000; Forevergen, Guangzhou, China), the immunoblots were exposed to enhanced chemiluminescence (ECL) reagent (Forevergen). The bands were quantified by optical density using glyceraldehyde-3-phosphate dehydrogenase (GAPDH) as a control. The primary antibodies were as follows: anti-Bcl-2 (CST2870; 1:1,000; Cell Signaling Technology, Inc., Danvers, MA, USA), anti-Bax (SC-493; 1:200; Santa Cruz Biotechnology, Santa Cruz, CA, USA), and antiGAPDH (HC301; 1:5,000; TransGen Biotech, Beijing, China).

Determination of apoptosis by flow cytometry. The apoptotic ratio was determined by flow cytometry with Annexin V-FITC/PI staining, according to manufacturer's instructions. Briefly, the NRCs were treated with P-1075 $(100 \mu \mathrm{M})$, HMR-1098 $(30 \mu \mathrm{M})$ and/or RR $(50 \mu \mathrm{M})$ for $24 \mathrm{~h}$ in the presence or absence of LPS $(25 \mu \mathrm{g} / \mathrm{ml})$. Following experimental treatment, the cells were collected, washed with calcium-free phosphate-buffered saline (PBS) and resuspended in binding buffer. The cells were treated with Annexin V-FITC and PI, left in the dark at room temperature for $15 \mathrm{~min}$, and analyzed using a Beckton-Dickinson flow cytometer (Navios; Beckman Coulter, Brea, CA, USA) [fluorescence-activated cell sorting (FACS) analysis].

Statistical analysis. Average values are presented in histograms and in the text as the means \pm SD. Data were analyzed using SPSS 11.5 for Windows (SPSS, Inc., Chicago, IL, USA). The total number of cells analyzed in each condition is given in the figure legends. The $t$ test was used to determine statistical significance. P-values in the figures are represented by asterisks.

\section{Results}

NRC culture and LPS exposure. After continuous culture for $24 \mathrm{~h}$, all adherent cardiac myocytes were spindle-, diamond- or polygonal-shaped and spontaneously beating at $60-100$ beats $/ \mathrm{min}$. The cells migrated across the surface and developed pseudopodia, forming irregular star shapes and weaving into a network of mutual contacts (data not shown). After $72 \mathrm{~h}$, the cultured cells were arranged in radial clusters (Fig. 1A) beating synchronously and autonomously at a rate of 100 beats $/ \mathrm{min}$. After stable growth for $24-48 \mathrm{~h}$, the cardiomyocytes were exposed to different concentrations of LPS $(0,5,25$ or $50 \mu \mathrm{g} / \mathrm{ml})$ for various time 


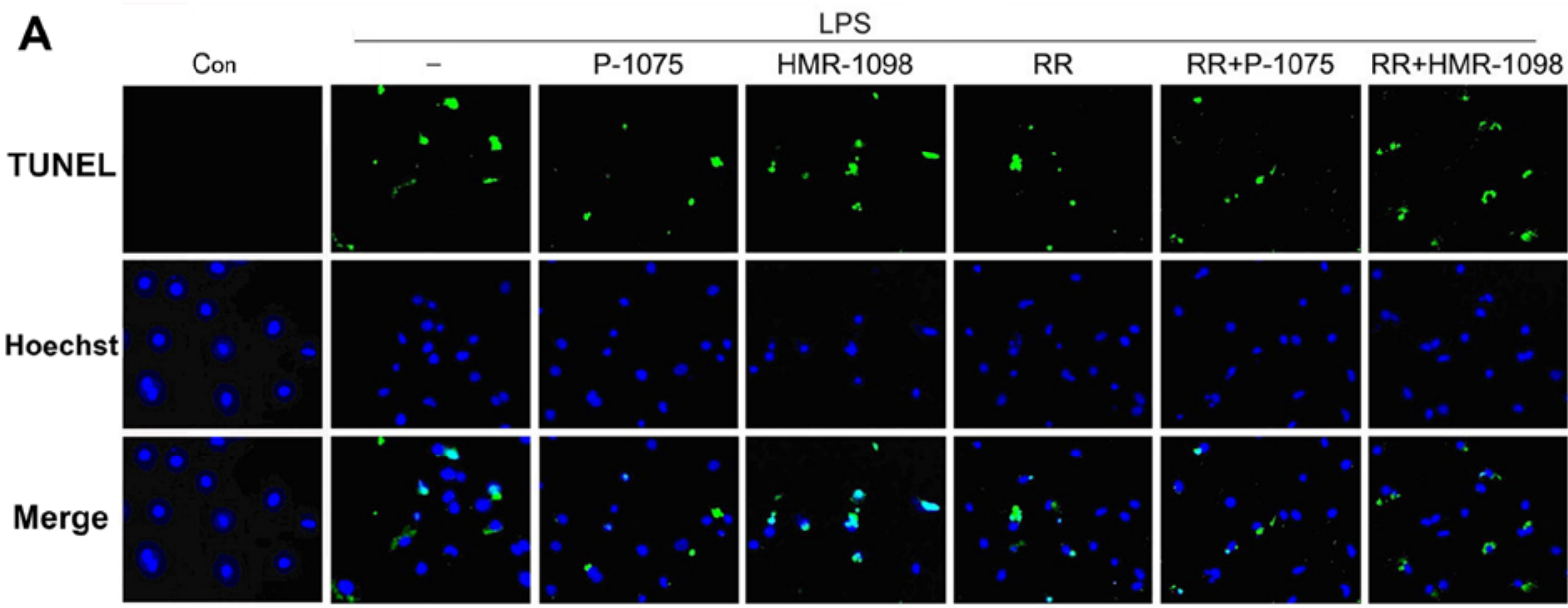

B

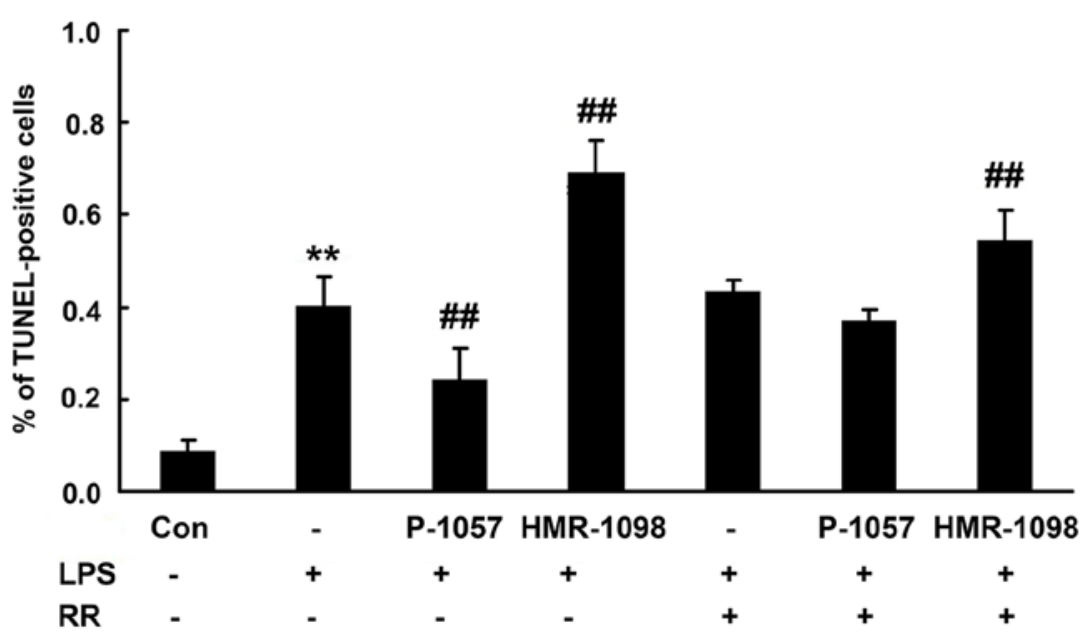

Figure 2. Effects of sarcolemmal ATP-sensitive $\mathrm{K}^{+}\left(\mathrm{sarcK}_{\mathrm{ATP}}\right)$ channel on the lipopolysaccharide (LPS)-induced apoptosis of neonatal rat cardiomyocytes (NRCs) detected by TUNEL assay. (A) Representative images of TUNEL staining of cardiomyocytes in each group. (B) The average percentage values of TUNEL-positive cells in each group. All values are presented as the means $\pm \mathrm{SD}$. ${ }^{* *} \mathrm{P}<0.01$ vs. control group (Con); ${ }^{\# \#} \mathrm{P}<0.01$ vs. LPS group. $\mathrm{n}=6$ in each group.

periods $(0,4,8$ and $24 \mathrm{~h})$ in order to determine the optimal observation window. The viability of the cardiomyocytes was determined using the MTT method, for the optimal dose and time duration of LPS exposure. We found that LPS induced cardiomyocyte death in a time- and concentration-dependent manner. Treating the myocytes with $25 \mu \mathrm{g} / \mathrm{ml}$ LPS for $24 \mathrm{~h}$ resulted in a nearly $60 \%$ survival rate (Fig. 1B), which was an appropriate observation window for the follow-up experiments.

Effects of sarc $K_{A T P}$ channel and mitochondrial calcium on the viability and LPS-induced apoptosis of NRCs. To determine whether further activation or inhibition of the sarcK $_{\text {ATP }}$ channel affected the viability and LPS-induced apoptosis of NRCs, the cells were exposed to $25 \mu \mathrm{g} / \mathrm{ml}$ LPS for $24 \mathrm{~h}$ followed by treatment with $100 \mu \mathrm{M} \mathrm{P}-1075$, $30 \mu \mathrm{M}$ HMR-1098 and $50 \mu \mathrm{M}$ RR.

Cellular viability is an important indicator of NRC injury. Following LPS exposure, cellular viability was $62.6 \pm 4.0 \%$, and significantly reduced compared with the control group $(\mathrm{P}<0.01)$. P-1075 markedly increased cellular viability to $71.3 \pm 7.1 \%$ ( $\mathrm{P}<0.05$, compared with the LPS group). HMR-1098 reduced cellular viability to $42.8 \pm 6.3 \%$ ( $\mathrm{P}<0.01$, compared with the LPS group). These results indicated that the $\operatorname{sarcK}_{\mathrm{ATP}}$ channel significantly preserved cellular viability (Fig. 1C).

Fig. 2A shows the TUNEL and Hoechst staining images of the NRCs. As shown in the bar graph in Fig. 2B, there was a significant increase in apoptosis in the LPS group compared with that in the control group $(40.1 \pm 6.7 \%$ in the LPS group vs. $8.7 \pm 2.6 \%$ in the control group, $\mathrm{P}<0.01$ ). The percentage of apoptotic cells was further increased in the presence of HMR-1098 $(69.3 \pm 6.9 \%$ in the LPS + HMR group, $\mathrm{P}<0.01$ compared with the LPS group). The percentage of apoptotic cells was decreased in the presence of P-1075 (24.3 $\pm 6.6 \%$ in the LPS + P group, $\mathrm{P}<0.01$ compared with LPS group). The application of RR resulted in the attenuation of LPS-induced apoptosis in the presence of HMR-1098 $(43.3 \pm 2.4 \%$ in the LPS + RR group and 54.7 $\pm 6.2 \%$ in the LPS + HMR + RR group, respectively, $\mathrm{P}<0.01$ vs. LPS + HMR group) and $\mathrm{P}-1075$ $(43.3 \pm 2.4 \%$ in the LPS + RR group and $37.0 \pm 2.4 \%$ ).

Effects of sarcK $K_{A T P}$ channel and mitochondrial calcium on caspase-3 activity in NRCs. LPS-induced apoptosis of cardiomyocytes is multifactorial. We examined the activity of caspase-3 in the NRCs. As shown in Fig. 3, caspase-3 


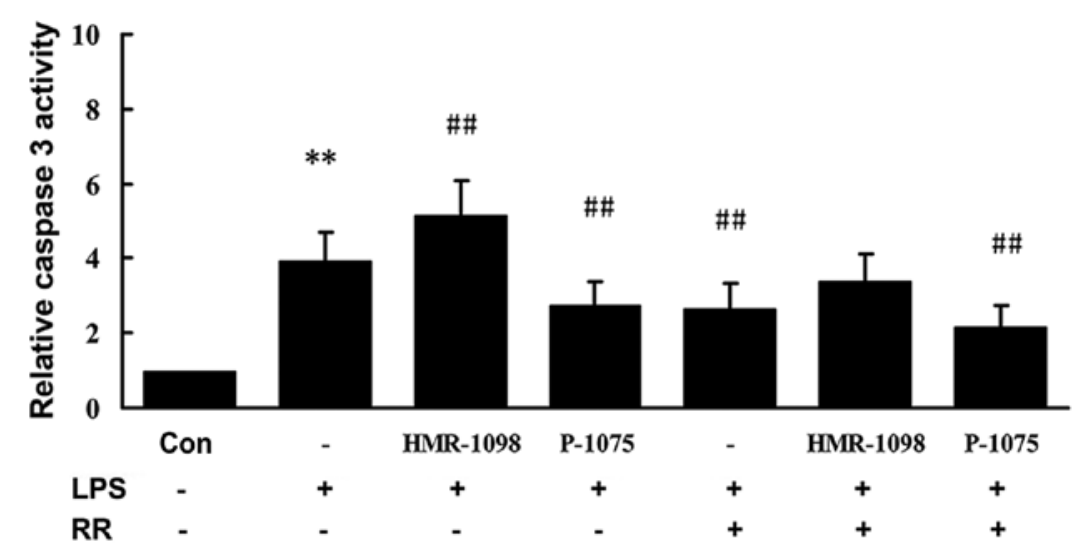

Figure 3. Effect of sarcolemmal ATP-sensitive $\mathrm{K}^{+}\left(\mathrm{sarcK}_{\mathrm{ATP}}\right.$ ) channel on caspase-3 activity in lipopolysaccharide (LPS)-exposed neonatal rat cardiomyocytes (NRCs). Relative caspase- 3 activity was calculated as the ratio of fluorescence intensity of treated cells to control cells, and the value of control was set to 1 . Results are shown as the means $\pm \mathrm{SD}$ from ten independent experiments for each protocol. ${ }^{* *} \mathrm{P}<0.01 \mathrm{vs.}$ control (Con) group; ${ }^{\# \#} \mathrm{P}<0.01$ vs. LPS group. $\mathrm{n}=6$ in each group.
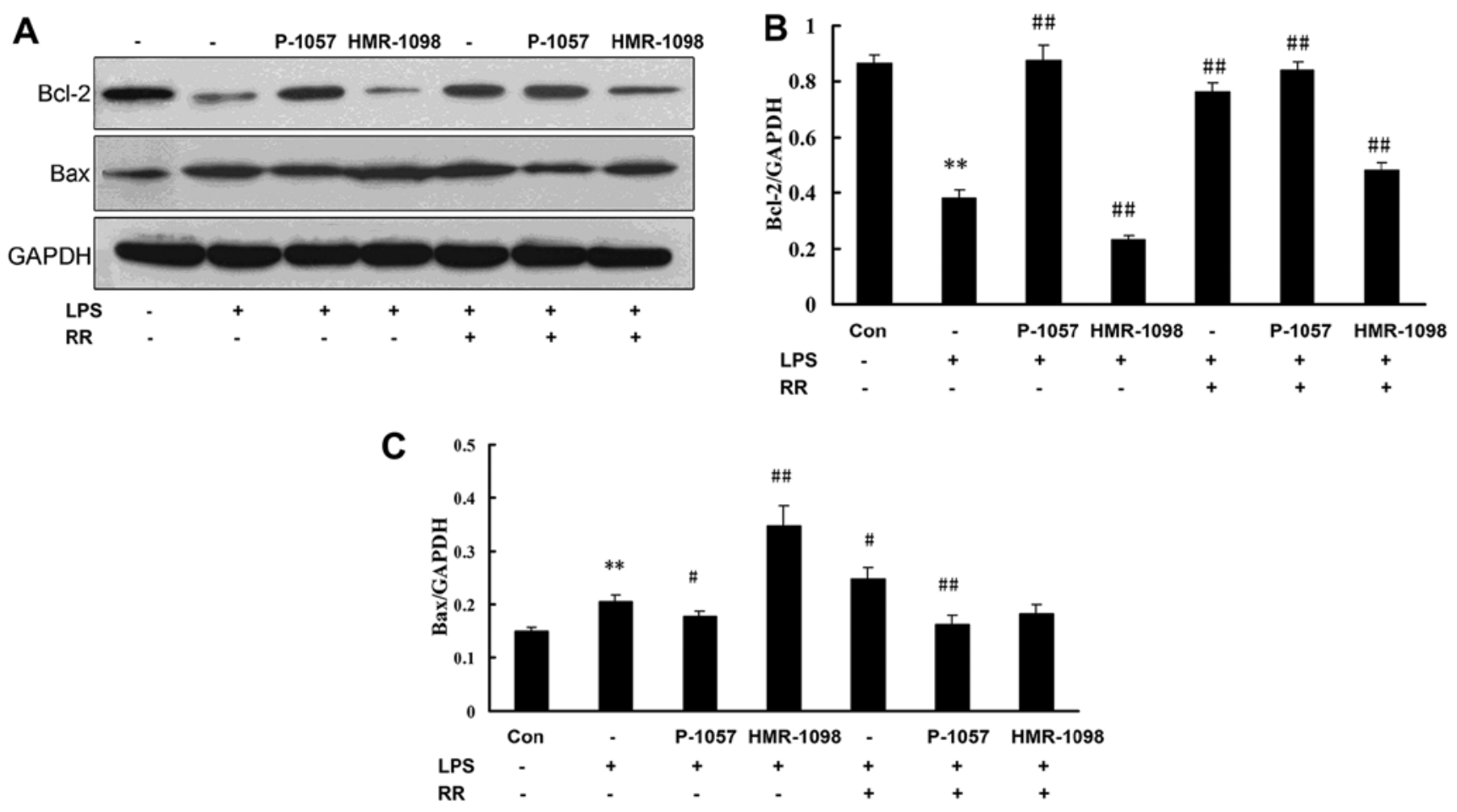

Figure 4. Effect of sarcolemmal ATP-sensitive $\mathrm{K}^{+}\left(\mathrm{sarcK}_{\mathrm{ATP}}\right)$ channel on Bcl-2 and Bax protein levels in lipopolysaccharide (LPS)-exposed neonatal rat cardiomyocytes (NRCs). (A) Bcl-2 and Bax protein expression of each group was detected by western blot analysis. Normalization of (B) Bcl-2 and (C) Bax protein expression to GAPDH. All values are presented as the means $\pm \mathrm{SD}$. ${ }^{* *} \mathrm{P}<0.01$ vs. control group (Con); ${ }^{\#} \mathrm{P}<0.05$ and ${ }^{\# \#} \mathrm{P}<0.01$ vs. LPS group. $\mathrm{n}=4-6$ in each group.

activity was markedly higher $24 \mathrm{~h}$ after LPS stimulation in the LPS group compared with that in the control group $(\mathrm{P}<0.01)$. Caspase- 3 activity was suppressed markedly in the LPS + P-1075 group compared with the LPS group $(\mathrm{P}<0.01)$. Caspase-3 activity was significantly increased in the LPS + HMR-1098 group ( $<<0.01$, compared with LPS group), which was partly attenuated in the presence of $50 \mu \mathrm{M} R \mathrm{R}$ ( $\mathrm{P}<0.01$, compared with the LPS group).

Effects of sarcK $K_{\text {ATP }}$ channel and mitochondrial calcium on the expression of the apoptosis-related proteins Bcl-2 and $B a x$. In order to determine whether the $\operatorname{sarcK}_{\text {ATP }}$ channel modulates some of the anti- and pro-apoptotic regulators, the protein levels of Bcl-2 and Bax were assessed in the present study by western blot analysis (Fig. 4A). As also shown in Fig. 4B and C, LPS stimulus downregulated Bcl-2 expression and upregulated Bax expression, and P-1075 increased the Bcl-2 protein level and decreased the Bax protein level in the LPS-exposed NRCs. By contrast, HMR-1098 decreased the Bcl-2 protein level and increased the Bax protein level in the LPS-exposed NRCs. The results suggested that sarcK $\mathrm{K}_{\mathrm{ATP}}$ prevented the apoptosis of NRCs by increasing Bcl-2 expression and inhibiting Bax expression (Fig. 4)

Effect of Kir6.2AAA overexpression on LPS-induced apoptosis. The recombinant adenovirus carrying the gene fragment 

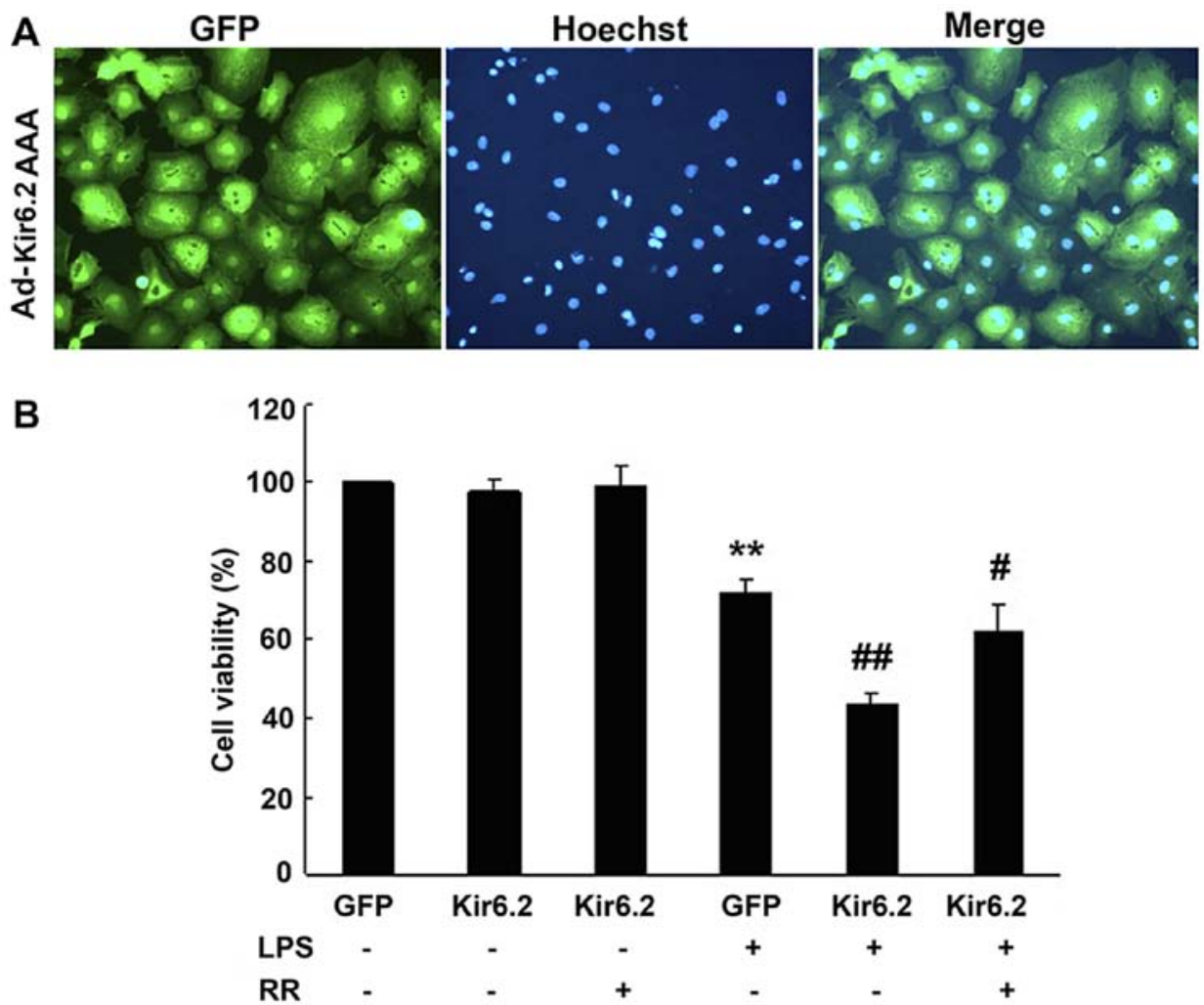

Figure 5. Effect of Kir6.2AAA overexpression on cell viability in neonatal rat cardiomyocytes (NRCs) exposed to lipopolysaccharide (LPS). (A) Ad-Kir6.2AAA infection of myocardial cells (x200 magnification). Inverted fluorescence microscope images show that in $>80 \%$ of the cells expressing GFP, the morphology of cells emitting light is clear ( $>80 \%$ of the infected cardiac myocytes showed strong green fluorescence signals), which suggests that infection was successful. (B) Average values of cell viability in different treatment groups as determined by the MTT assay. All values are presented as the means $\pm \mathrm{SD}$. ${ }^{* *} \mathrm{P}<0.01 \mathrm{vs}$. GFP group; ${ }^{\#} \mathrm{P}<0.05$ and ${ }^{\# \#} \mathrm{P}<0.01$ vs. GFP + LPS group. $\mathrm{n}=6$ in each group.

Kir6.2AAA and GFP was constructed successfully, with a viral titer of $2.64 \times 10^{11} \mathrm{VP} / \mathrm{ml}$. Following infection with recombinant adenovirus Kir6.2AAA, the rat myocytes expressed GFP and emitted green fluorescence (Fig. 5A). The expression of Kir6.2AAA was significantly upregulated in recombinant adenovirus vector Ad-Kir6.2AAA-infected myocytes and this was confirmed by RT-PCR (data not shown). The increased expression of Kir6.2AAA was confirmed in rat myocytes by western blot analysis, which suggested that the recombinant adenovirus carrying the gene fragment Kir6.2AAA and GFP was constructed successfully and expressed correctly in the rat myocytes (data not shown).

Adenovirus infection has little effect on cellular viability. Following LPS exposure, cellular viability of the GFP + LPS group was significantly reduced $(72.1 \pm 3.6 \%)$ compared with the GFP group $(\mathrm{P}<0.01)$. Overexpression of Kir6.2AAA (Kir6.2 group) markedly reduced the cellular viability to $43.4 \pm 2.8 \%(\mathrm{P}<0.01$, compared with GFP + LPS group) RR treatment increased the cellular viability to $62.0 \pm 6.9 \%$ $(\mathrm{P}<0.05$, compared with GFP + LPS group) (Fig. 5B).

Apoptosis was measured by flow cytometry (Fig. 7A). Adenovirus infection had little effect on myocardial apoptosis:

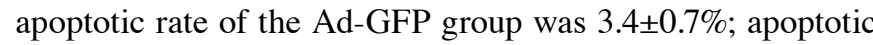
rate of the Ad-Kir6.2AAA group was 3.7 $\pm 0.7 \%$; apoptotic rate

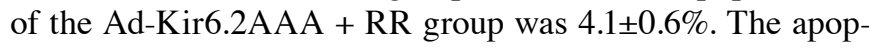
totic rate of the myocytes significantly increased following LPS exposure: apoptotic rate of the Ad-GFP + LPS group was $14.9 \pm 2.8 \%$; apoptotic rate of the Ad-Kir6.2AAA + LPS was
$36.0 \pm 3.8 \%$; apoptotic rate of the Ad-Kir6.2AAA + RR + LPS group was $19.4 \pm 3.7 \%$ (Fig. 7B). The results suggested that in the model of LPS-induced apoptosis in NRCs, overexpression of Kir6.2AAA further promoted the apoptosis of myocytes, and RR treatment protected the myocytes from LPS-induced apoptosis.

The effect of Kir6.2AAA overexpression on Bcl-2 and Bax protein levels was detected by western blot analysis (Fig. 6A). Our results showed that adenovirus infection has no effect on the protein expression of Bcl-2 and Bax. LPS downregulated Bcl-2 expression and upregulated Bax expression in the GFP + LPS group. Overexpression of Kir6.2AAA (Kir6.2 group) markedly decreased the Bcl-2 protein level and increased the Bax protein level in the LPS-exposed NRCs (Fig. 6B and C). RR treatment increased the $\mathrm{Bcl}-2$ protein level and decreased the Bax protein level in the LPS-exposed NRCs (Fig. 6).

\section{Discussion}

In the present study, we examined the role of the $\operatorname{sarcK} \mathrm{K}_{\mathrm{ATP}}$ channel in the LPS-induced apoptosis of NRCs. Our findings suggest that the $\operatorname{sarcK}_{\mathrm{ATP}}$ channel exerts a cardioprotective effect against apoptosis induced by LPS and is mediated by mitochondrial $\mathrm{Ca}^{2+}$ in rat cardiomyocytes.

The protective role of the $\operatorname{sarcK}_{\text {ATP }}$ channels has been proposed since the time of their discovery due to their ability to sense intracellular metabolic conditions (15). In 1983, Noma (5) identified a $\mathrm{K}_{\mathrm{ATP}}$ channel in membrane patches 

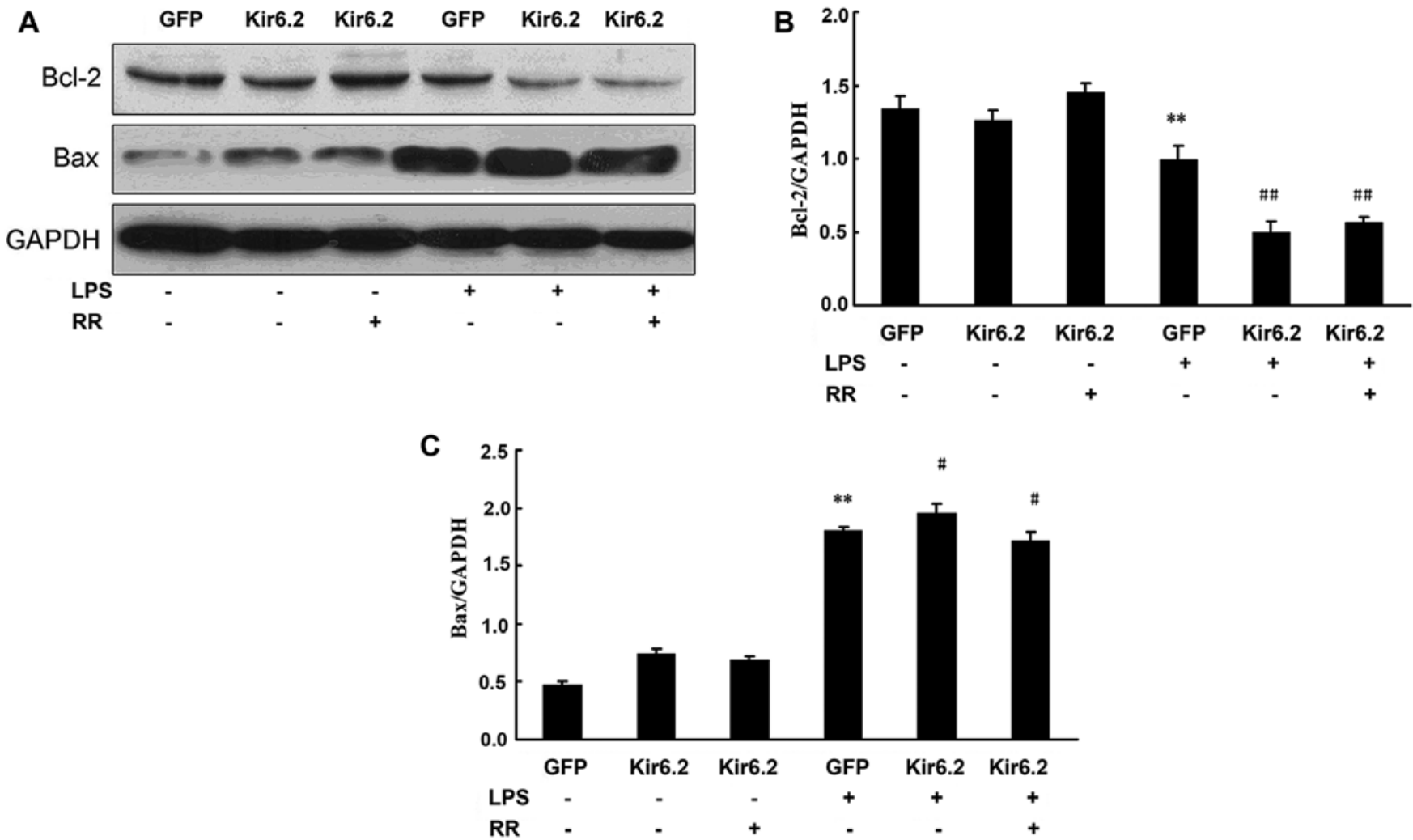

Figure 6. Effect of Kir6.2AAA overexpression on Bcl-2 and Bax protein levels in lipopolysaccharide (LPS)-exposed neonatal rat cardiomyocytes (NRCs) (A) Bcl-2 and Bax protein expression was detected by western blot analysis. Normalization of (B) Bcl-2 and (C) Bax protein expression to GAPDH. All values are presented as the means $\pm \mathrm{SD} .{ }^{* *} \mathrm{P}<0.01$ vs. GFP group; ${ }^{*} \mathrm{P}<0.05$ and ${ }^{\# \#} \mathrm{P}<0.01$ vs. GFP + LPS group. $\mathrm{n}=4-6$ in each group.

prepared from isolated guinea pig ventricular myocytes. Subsequently, $\mathrm{K}_{\mathrm{ATP}}$ channels were discovered in other tissues, including the brain, smooth muscle, skeletal muscle, intestine, kidney and pancreas. The channel coupled myocardial energy metabolism to membrane electrochemistry, which highlighted its role in all types of ion channels. The metabolic gating of the sarcK $\mathrm{K}_{\text {ATP }}$ channel is attributed to its molecular composition. Structurally, $\mathrm{K}_{\mathrm{ATP}}$ channels are composed of two distinct proteins, an inwardly rectifying potassium channel (Kir) pore subunit and the sulfonylurea receptor (SUR), which may have a regulatory role in modulating the sensitivity of the channel to ATP, other nucleotides, and pharmacological agonists or antagonists (16). The cardiac sarcolemmal $\mathrm{K}_{\mathrm{ATP}}$ channel is composed of an octomeric complex of two types of subunits, the Kir6.2 and the SUR2A subunit.

The cardiac sarcK ${ }_{\text {АтP }}$ channel is the sensory receptor of cellular energy metabolism and highly sensitive to fluctuations in its microenvironment. It is blocked by ATP in the cell, normally closed, and opened under various pathological or stress conditions. ATP production is reduced in sepsis, myocardial ischemia and hypoxia as well as other stress conditions, which results in the channel opening followed by cell membrane hyperpolarization, closing of voltage-dependent $\mathrm{Ca}^{2+}$ channels and reduced internal calcium current. Simultaneously, the opening of sarcK $\mathrm{K}_{\text {АTP }}$ channels causes the outflow of $\mathrm{K}^{+}$and accelerated repolarization, which results in shortening the duration of the cellular action potential and reduced inflow of $\mathrm{Ca}^{2+}$. In addition, due to the increase in ion outflow and rapid recovery of resting membrane potential, $\mathrm{Ca}^{2+}$ is easily released into the cytoplasm by $\mathrm{Na}^{+} / \mathrm{Ca}^{2+}$ exchange under a lower resting membrane potential. These mechanisms alleviate the extent of cellular damage from cytosolic $\mathrm{Ca}^{2+}$ overload. On the other hand, intracellular myocardial $\left[\mathrm{Ca}^{2+}\right]$ i levels are reduced, leading to depression of the myocardical contraction, thereby reducing the cellular ATP consumption (5). Thus, sarcK $\mathrm{K}_{\text {ATP }}$ channels mediate endogenous protective effects in myocytes by sensing and regulating the cellular levels of energy metabolism through electrical feedback, which helps the myocytes survive metabolic crisis. Genetic deletion or alterations to the Kir6.2 subunit of the sarcK $\mathrm{ATP}_{\text {AT }}$ channel results in a loss of both ischemic preconditioning and adaptation to stress (16-19) In addition, a reduction in the number of functional sarcK ${ }_{\text {ATP }}$ channels eliminates the transient action potentials during metabolic inhibition, leading to reduced metabolic stress tolerance, and increased $\mathrm{Ca}^{2+}$ loading during metabolic inhibition (20).

The role of sarcK $\mathrm{K}_{\text {АтP }}$ channels in cardiac sepsis remains poorly understood. Many scholars have confirmed that the channel was activated or upregulated in response to LPS challenge. Since the sarcK $\mathrm{ATP}_{\text {}}$ channel plays an important role in maintaining cellular homeostasis, it mediates several cellular pathological and physiological activities, such as apoptosis. In the present study, P-1075, a selective sarcK $_{\text {ATP }}$ opener, reduced LPS-induced apoptosis. By contrast, HMR-1098, a selective sarcK $_{\text {ATP }}$ blocker, or the overexpression of Kir6.2AAA increased LPS-induced apoptosis in the cultured NRCs, as measured by flow cytometry and the TUNEL assay, which was consistent with the results of a previous study (10). LPS induced the apoptosis of cardiomyocytes. The sarcK $\mathrm{K}_{\text {ATP }}$ 
A
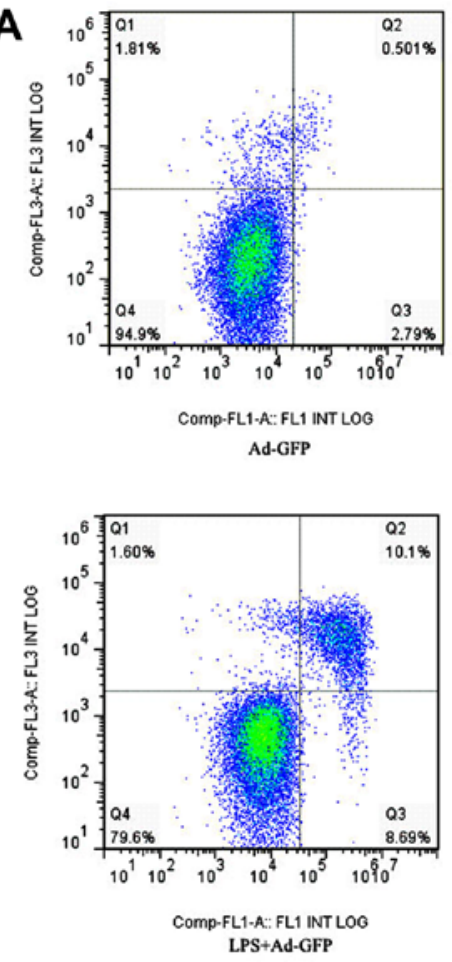

B
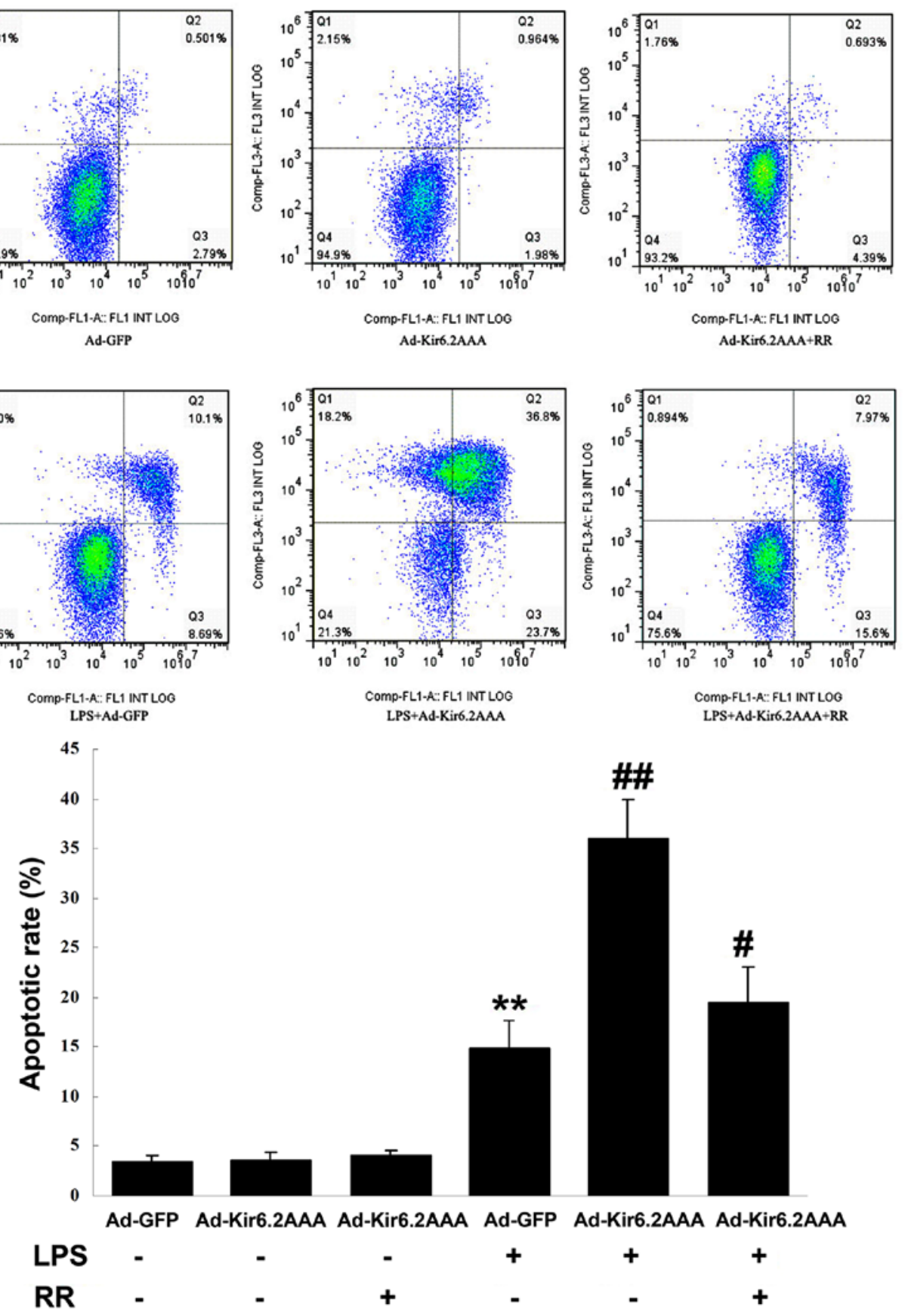

Figure 7. Overexpression of Kir6.2AAA promotes lipopolysaccharide (LPS)-induced apoptosis. (A) Representative flow cytometric analysis of apoptosis shows that overexpression of Kir6.2AAA promoted LPS-induced apoptosis. Treatment with ruthenium red (RR) blocked the effect. (B) Quantitative analysis of apoptosis by flow cytometry $(\mathrm{n}=6) .{ }^{* *} \mathrm{P}<0.01$ vs. Ad-GFP group; ${ }^{\#} \mathrm{P}<0.05$ vs. Ad-GFP + LPS group; ${ }^{\# \#} \mathrm{P}<0.01$ vs. Ad-GFP + LPS group.

channel prevented the apoptosis of cardiomyocytes induced by oxidative stress (21) and the apoptosis of the bladder smooth muscle induced by acute urinary retention (22). The channel also exerts a protective effect against ischemia-reperfusion-induced apoptosis in testicular damage (23).

As the cellular power houses, mitochondria are not only associated closely with the sarcK ${ }_{\text {ATP }}$ channel, but play a central role in apoptosis. Since mitochondria generate the majority of cellular ATP and its metabolite ADP in the cell, which are the main regulating factors of sarcK $\mathrm{ATP}_{\mathrm{AT}}$ channels, mitochondria invariably affect the activity of $\operatorname{sarcK}_{\text {ATP }}$ channels. On the other hand, mitochondria also regulate ionic steady state in the cell. Under different stress conditions, mitochondria act as a buffer and reduce intracellular $\mathrm{Ca}^{2+}$ overload. However, uncontrolled $\mathrm{Ca}^{2+}$ overload initiates cell death including apoptosis (24). Mitochondrial $\mathrm{Ca}^{2+}$ overload triggers the opening of the mitochondrial permeability transport channel (mPTP), and the mitochondrial permeability transition (MPT), followed by phagocy tosis by lysosomes. When a large number of mitochondria reach MPT, cytochrome $\mathrm{c}$ and apoptosis-inducing factor enter the cytoplasm, to activate cellular apoptosis, and even necrosis (25). In sepsis, mitochondrial function is impaired in cardiomyocytes and ATP production is reduced, which decreases sarcoplasm/endoplasmic reticulum (S/ER) calcium ATPase (SERCA) activity, leading to reduced levels of $\mathrm{Ca}^{2+}$ in the S/ER, increased levels of cytoplasmic $\mathrm{Ca}^{2+}$, resulting 
in mitochondrial $\mathrm{Ca}^{2+}$ accumulation (26). Opening sarcK $\mathrm{K}_{\mathrm{ATP}}$ channels reduces intracellular $\mathrm{Ca}^{2+}$ overload by cell membrane hyperpolarization, shortening the action potential duration. Stimulating $\mathrm{Na}^{+}-\mathrm{Ca}^{2+}$ exchange also affects the mitochondrial $\mathrm{Ca}^{2+}$ load. In the present study, the mitochondrial calcium transport inhibitor RR partially attenuated the pro-apoptotic effect of HMR-1098. The results suggested that the mitochondrial pathway is involved in the $\operatorname{sarcK}_{\mathrm{ATP}}$-channel-mediated apoptosis of NRCs induced by LPS.

The present study provides new evidence correlating sarcK $_{\text {ATP }}$ channel activity with downstream mitochondrial function. By elucidating the mechanism responsible for the sarcK $_{\text {ATP }}$ channel-mediated regulation of apoptosis, we have provided a new perspective for the possible pathogenesis of sepsis being associated with cardiac dysfunction, which should facilitate the development of novel targeted therapies and strategies.

\section{Acknowledgements}

This study was supported by the grants from the National Natural Science Foundation of China (no. 81101450)

\section{References}

1. Merx MW and Weber C: Sepsis and the heart. Circulation 116: 793-802, 2007

2. Zanotti-Cavazzoni SL and Hollenberg SM: Cardiac dysfunction in severe sepsis and septic shock. Curr Opin Crit Care 15 392-397, 2009

3. Lancel S, Joulin O, Favory R, Goossens JF, Kluza J, Chopin C, Formstecher P, Marchetti P and Neviere R: Ventricular myocyte caspases are directly responsible for endotoxin-induced cardiac dysfunction. Circulation 111: 2596-2604, 2005.

4. Suzuki J, Bayna E, Dalle Molle E and Lew WY: Nicotine inhibits cardiac apoptosis induced by lipopolysaccharide in rats. J Am Coll Cardiol 41: 482-488, 2003.

5. Noma A: ATP-regulated $\mathrm{K}^{+}$channels in cardiac muscle. Nature 305: 147-148, 1983.

6. Zhou F, Yao HH, Wu JY, Ding JH, Sun T and Hu G: Opening of microglial K(ATP) channels inhibits rotenone-induced neuroinflammation. J Cell Mol Med 12: 1559-1570, 2008.

7. Liu H,Zhang HY,Zhu X, ShaoZ Zand YaoZ: Preconditioning blocks cardiocyte apoptosis: role of $\mathrm{K}_{(\mathrm{ATP})}$ channels and PKC-epsilon. Am J Physiol Heart Circ Physiol 282: H1380-H1386, 2002.

8. Kane GC, Liu XK, Yamada S, Olson TM and Terzic A: Cardiac $\mathrm{K}_{\mathrm{ATP}}$ channels in health and disease. J Mol Cell Cardiol 38: 937-943, 2005.

9. Buckley JF, Singer M and Clapp LH: Role of $\mathrm{K}_{\text {ATP }}$ channels in sepsis. Cardiovasc Res 72: 220-230, 2006.

10. Yang ZW, Chen JK, Ni M, Zhao T, Deng YP, Tao X, Jiang GJ and Shen FM: Role of Kir6.2 subunits of ATP-sensitive potassium channels in endotoxemia-induced cardiac dysfunction. Cardiovasc Diabetol 12: 75, 2013.

11. Kuo JH, Chen SJ, Shih CC, Lue WM and Wu CC: Abnormal activation of potassium channels in aortic smooth muscle of rats with peritonitis-induced septic shock. Shock 32: 74-79, 2009.
12. Shi W, Cui N, Wu Z, Yang Y, Zhang S, Gai H, Zhu D and Jiang C: Lipopolysaccharides up-regulate Kir6.1/SUR2B channel expression and enhance vascular $\mathrm{K}_{\mathrm{ATP}}$ channel activity via NF-kappaB-dependent signaling. J Biol Chem 285: 3021-3029, 2010.

13. Charalambous BM, Stephens RC, Feavers IM and Montgomery HE: Role of bacterial endotoxin in chronic heart failure: the gut of the matter. Shock 28: 15-23, 2007.

14. Shen M, Wu RX, Zhao L, Li J, Guo HT, Fan R, Cui Y, Wang YM, Yue SQ and Pei JM: Resveratrol attenuates ischemia/reperfusion injury in neonatal cardiomyocytes and its underlying mechanism. PLoS One 7: e51223, 2012.

15. Nichols CG: $K_{\text {ATP }}$ channels as molecular sensors of cellular metabolism. Nature 440: 470-476, 2006.

16. Sellitto AD, Al-Dadah AS, Schuessler RB, Nichols CG and Lawton JS: Anopen sarcolemmaladenosinetriphosphate-sensitive potassium channel is necessary for detrimental myocyte swelling secondary to stress. Circulation 124 (Suppl 11): S70-S74, 2011.

17. Suzuki M, Sasaki N, Miki T, Sakamoto N, Ohmoto-Sekine Y, Tamagawa M, Seino S, Marbán E and Nakaya H: Role of sarcolemmal K(ATP) channels in cardioprotection against ischemia/reperfusion injury in mice. J Clin Invest 109: 509-516, 2002.

18. Zingman LV, Hodgson DM, Bast PH, Kane GC, Perez-Terzic C, Gumina RJ, Pucar D, Bienengraeber M, Dzeja PP, Miki T, et al: Kir6.2 is required for adaptation to stress. Proc Natl Acad Sci USA 99: 13278-13283, 2002.

19. Gumina RJ, Pucar D, Bast P, Hodgson DM, Kurtz CE, Dzeja PP Miki T, Seino S and Terzic A: Knockout of Kir6.2 negates ischemic preconditioning-induced protection of myocardial energetics. Am J Physiol Heart Circ Physiol 284: H2106-H2113, 2003.

20. Rainbow RD, Lodwick D, Hudman D, Davies NW, Norman RI and Standen NB: SUR2A C-terminal fragments reduce $K_{\text {ATP }}$ currents and ischaemic tolerance of rat cardiac myocytes. J Physiol 557: 785-794, 2004.

21. Marinovic J, Ljubkovic M, Stadnicka A, Bosnjak ZJ and Bienengraeber M: Role of sarcolemmal ATP-sensitive potassium channel in oxidative stress-induced apoptosis: mitochondrial connection. Am J Physiol Heart Circ Physiol 294: H1317-H1325, 2008.

22. Ohmasa F, Saito M, Oiwa H, Tsounapi P, Shomori K, Kitatani K, Dimitriadis F, Kinoshita Y and Satoh K: Pharmacological preconditioning of ATP-sensitive potassium channel openers on acute urinary retention-induced bladder dysfunction in the rat. BJU Int 110: E245-E252, 2012.

23. Tsounapi P, Saito M, Dimitriadis F, Kitatani K, Kinoshita Y, Shomori K, Takenaka A and Satoh K: The role of K ATP channels on ischemia-reperfusion injury in the rat testis. Life Sci 90: 649-656, 2012.

24. Dorn GW II: Apoptotic and non-apoptotic programmed cardiomyocyte death in ventricular remodelling. Cardiovasc Res 81: 465-473, 2009.

25. Nishida K, Yamaguchi O and Otsu K: Crosstalk between autophagy and apoptosis in heart disease. Circ Res 103: 343-351, 2008.

26. Hassoun SM, Marechal X, Montaigne D, Bouazza Y, Decoster B, Lancel S and Neviere R: Prevention of endotoxin-induced sarcoplasmic reticulum calcium leak improves mitochondrial and myocardial dysfunction. Crit Care Med 36: 2590-2596, 2008. 